\title{
EL PRINCIPIO DE LIBERTAD DE EXPRESIÓN EN LAS REDES SOCIALES Y SU REGULACIÓN EN EL ORDENAMIENTO JURÍDICO ECUATORIANO
}

\section{THE PRINCIPLE OF FREEDOM OF EXPRESSION IN SOCIAL NETWORKS AND ITS REGULATION IN THE ECUADORIAN LEGAL ORDERING}

\begin{abstract}
Abg. Mercedes Coronel Gómez, Mgs.
Magíster en Planificación, Acreditación y Evaluación de la Educación Superior especialista en Derecho Civil, Contratos y Propiedad Intelectual (Ecuador). Docente Tiempo Completo de la Facultad de Derecho y Gobernabilidad de la Universidad Tecnológica ECOTEC, Ecuador. mecoronel@ecotec.edu.ec
\end{abstract}

\section{ARTÍCULO DE REFLEXIÓN}

Recibido: 9 de septiembre de 2019.

Aceptado: 17 de octubre de 2019.

\section{RESUMEN}

La administración de justicia en el Ecuador se ha visto profundamente afectada con el ingreso y actualización de las nuevas tecnologías de la información y las comunicaciones (TIC); hoy en día, existe un nuevo concepto que involucra a la sociedad que son las redes sociales y que afecta tanto a los particulares como a la sociedad, así como a la administración de justicia y que están ligadas actualmente a un derecho amparado tanto en la Constitución Política del Ecuador como en la ley orgánica de Comunicación ecuatoriana que corresponde a la libertad de expresión; derecho existente en normativas nacionales e internacionales. La libertad de expresión, está recopilada en la Declaración Universal de Derechos Humanos y las leyes de los países miembros que han acordado respetarla tanto en su legislación como en tratados y pactos internacionales. Es importante establecer que el derecho a la libertad de expresión no es un derecho absoluto. Por lo tanto, las leyes pueden delimitar su campo de acción en respeto de los derechos de los 
demás. El ordenamiento jurídico en el Ecuador está atrasado en cuanto a los avances tecnológicos, es importante plantear un estudio que analice tanto el ámbito de las redes sociales como su relación con la libertad de expresión en el Ecuador; generando información producto de un proceso de investigación que sustente una propuesta que desarrolle un marco legal adecuado para este ámbito en el Ecuador.

Palabras clave: Libertad, Expresión, Redes Sociales, Internet, Normativa.

\section{ABSTRACT}

The administration of justice in Ecuador has seen profound modifications with the entry and updating of new information and communications technologies (ICT); Today, there is a new concept that involves society that are social networks and that affects both individuals and society, as well as the administration of justice and that are currently linked to a right protected both in the Political Constitution of Ecuador as in the organic law of Ecuadorian Communication that corresponds to freedom of expression; existing law in national and international regulations. Freedom of expression is compiled in the Universal Declaration of Human Rights and the laws of the member countries that have agreed to respect it both in their legislation and in international treaties and covenants. It is important to establish the right to freedom of expression is not an absolute right. Therefore, laws can delimit their field of action in respect for the rights of others.

The legal system in Ecuador has a significant delay in the relationship with technological advances, it is important to propose a study that analyzes both the scope of social networks and their relationship with freedom of expression in Ecuador; generating information resulting from a research process that supports a proposal that develops an appropriate legal framework for this area in Ecuador.

Keywords: Freedom, Expression, Social Networks, Internet, Regulation

\section{INTRODUCCIÓN}

La administración de justicia en el Ecuador se ha visto profundamente afectada con el ingreso y actualización de las nuevas tecnologías de la información y las comunicaciones (TIC); los dispositivos informáticos y los computadores personales interconectados en la red mundial denominada internet son el signo más evidente del impacto que tiene en la sociedad las 
telecomunicaciones, el indispensable tráfico económico y comercial, el uso de estas tecnologías son prácticamente indispensables. Hoy en día, existe un nuevo concepto que involucra a la sociedad que son las redes sociales y que plantea un nuevo paradigma que afecta tanto a los particulares como a la sociedad, así como a la administración de justicia.

Este nuevo concepto está intrínsecamente ligado a un derecho amparado tanto en la Constitución Política del Ecuador como en la ley orgánica de Comunicación ecuatoriana que corresponde a la libertad de expresión; derecho existente en normativas nacionales e internacionales. Este derecho en la sociedad de hoy denominado libertad de expresión, está recopilada en la Declaración Universal de Derechos Humanos y las leyes de los países que viven en democracia y que han acordado tanto en su legislación como tratados y pactos internacionales. Pero es importante tener establecido, que el derecho a la libertad de expresión no es un derecho absoluto. Por lo tanto, las leyes pueden prohibir, por ejemplo, que una persona incite a la violencia o viole la intimidad de las personas y puede conllevar inclusive una pena privativa de libertad debido a la responsabilidad ulterior que se tiene al haber ejercido su derecho a expresarse.

Es importante señalar que, aunque se ha institucionalizado y se perciba que todo lo que existe o se realice en internet va de la mano con la libertad de expresión y por ende no tiene consecuencias legales, esto en la práctica no es cierto, si bien todas las personas tienen derechos, también tienen obligaciones con los demás en sociedad. Al ser un concepto nuevo y el ordenamiento jurídico en el Ecuador tiene un retraso en relación con los avances tecnológicos, es importante plantear un estudio que analice tanto el ámbito de las redes sociales como su relación con la libertad de expresión en el Ecuador; generando información que sustente una propuesta que desarrolle un marco legal adecuado para este ámbito en el país.

\section{REVISIÓN TEÓRICA}

\section{La libertad de expresión en la actualidad}

Por su importancia en la sociedad de hoy, la libertad de expresión, está recopilada en la Declaración Universal de Derechos Humanos y las leyes de los países que viven en democracia. Pero es importante estar consciente, que el derecho a la libertad de expresión no es un derecho 
absoluto. Por lo tanto, las leyes pueden prohibir, por ejemplo, que una persona incite a la violencia o viole la intimidad de las personas y puede conllevar inclusive una pena privativa de libertad debido a la responsabilidad ulterior que se tiene al haber ejercido su derecho a expresarse.

Hoy en día existe una tendencia a contar la vida personal en las redes sociales a través de fotografías o videos los cuales pueden ser personales o en su defecto de terceros. Esto supone un riesgo en el sentido de que cualquiera tiene acceso a ellas y hacer un uso de las mismas sin nuestro expreso consentimiento. Además, diariamente se está expuesto a las cámaras de los celulares o cualquier dispositivo móvil, que pueden retratarnos sin darnos cuenta, especialmente si se trata de una imagen o video que comprometa la integridad, intimidad o genere una falsa acusación hacia un tercero involucrado.

Actualmente, Ecuador no posee una Ley especial para los delitos informáticos o de tecnología; sin embargo, la norma penal ecuatoriana define el derecho a la intimidad personal y familiar y puede ser sancionado aplicando el Código Orgánico Integral Penal (COIP) en su Artículo 178 de la Violación a la intimidad que establece que la persona sin contar con el consentimiento o la autorización legal, que acceda, intercepte, examine, retenga, grabe, reproduzca, difunda o publique datos personales, mensajes de datos, voz, audio y vídeo, objetos postales, información contenida en soportes informáticos, comunicaciones privadas o reservadas de otra persona por cualquier medio será sancionada con pena privativa de libertad de uno a tres años. Es importante señalar que no es aplicable esta norma para la persona que divulgue grabaciones de audio y vídeo en las que interviene personalmente, ni cuando se trata de información pública de acuerdo con lo previsto en la ley.

\section{Legislación internacional sobre libertad de expresión aplicable en el Ecuador Declaración Universal de Derechos Humanos.}

De acuerdo a la Carta de las Naciones Unidas pueden ser Miembros de la ONU todos los países amantes de la paz que acepten las obligaciones previstas en ella y que, a juicio de la 
Organización, sean capaces de cumplir esas obligaciones y estén dispuestos a hacerlo ${ }^{1}$. El Ecuador pasó a formar parte de la ONU como estado miembro el 21 de diciembre de 1945, como estado miembro el Ecuador tiene la obligación de cumplir con la Declaración Universal de derechos Humanos proclamada el 10 de diciembre de 1948 y en la cual establece en sus artículos 19 y 29.

\section{Artículo 19}

Todo individuo tiene derecho a la libertad de opinión y de expresión; este derecho incluye el no ser molestado a causa de sus opiniones, el de investigar y recibir informaciones y opiniones, y el de difundirlas, sin limitación de fronteras, por cualquier medio de expresión. ${ }^{2}$

\section{Artículo 29}

En su numeral 2 establece que: En el ejercicio de sus derechos y en el disfrute de sus libertades, toda persona estará solamente sujeta a las limitaciones establecidas por la ley con el único fin de asegurar el reconocimiento y el respeto de los derechos y libertades de los demás, y de satisfacer las justas exigencias de la moral, del orden público y del bienestar general en una sociedad democrática.

En su numeral 3 establece que: Estos derechos y libertades no podrán en ningún caso ser ejercidos en oposición a los propósitos y principios de las Naciones Unidas. ${ }^{3}$

El documento establecido como Declaración Universal de los Derechos Humanos corresponde a un ámbito orientativo para los estados miembros; a partir de la firma del Pacto internacional de derechos civiles y políticos que entró en vigor el 23 de marzo de 1976 y que establece en relación a la libertad de expresión en sus artículos 19 y 20:

\footnotetext{
${ }^{1}$ Organización de las Naciones Unidas ONU; Carta de las Naciones Unidas Artículo 4 - 1945

${ }^{2}$ Organización de las Naciones Unidas ONU; Artículo 19 de la Declaración Universal de derechos Humanos - 1948

${ }^{3}$ Organización de las Naciones Unidas ONU; Artículo 29 de la Declaración Universal de derechos Humanos - 1948
} 


\section{Pacto internacional de derechos civiles y políticos}

\section{Artículo 19}

1. Nadie podrá ser molestado a causa de sus opiniones.

2. Toda persona tiene derecho a la libertad de expresión; este derecho comprende la libertad de buscar, recibir y difundir informaciones e ideas de toda índole, sin consideración de fronteras, ya sea oralmente, por escrito o en forma impresa o artística, o por cualquier otro procedimiento de su elección.

3. El ejercicio del derecho previsto en el párrafo 2 de este artículo entraña deberes y responsabilidades especiales. Por consiguiente, puede estar sujeto a ciertas restricciones, que deberán, sin embargo, estar expresamente fijadas por la ley y ser necesarias para:

a) Asegurar el respeto a los derechos o a la reputación de los demás;

b) La protección de la seguridad nacional, el orden público o la salud o la moral públicas. ${ }^{4}$

\section{Artículo 20}

1. Toda propaganda en favor de la guerra estará prohibida por la ley.

2. Toda apología del odio nacional, racial o religioso que constituya incitación a la discriminación, la hostilidad o la violencia estará prohibida por la ley. ${ }^{5}$

La declaración universal de Derechos Humanos y los pactos Internacionales correspondientes comprende lo que denominamos la carta Internacional de Derechos Humanos. Los pactos internacionales como el Pacto Internacional de Derechos civiles y Políticos se los consideran tratados internacionales y en la cual los estados firmantes están obligados a cumplir.

\footnotetext{
${ }^{4}$ Organización de las Naciones Unidas ONU; Artículo 19 del Pacto Internacional de Derechos Civiles y Políticos Firmado en 1966 y entrado en vigor en 1976

${ }^{5}$ Organización de las Naciones Unidas ONU; Artículo 20 del Pacto Internacional de Derechos Civiles y Políticos Firmado en 1966 y entrado en vigor en 1976
}

ISSN: 1390-9320, Edición Especial, diciembre 2019 


\section{Convención sobre los Derechos del Niño}

La convención sobre los derechos del niño es un tratado internacional de la Naciones Unidas mediante el cual se establece que los niños poseen los mismos derechos que los adultos, y se enfatiza en los derechos generados por su condición de seres humanos que, por no haber alcanzado el pleno desarrollo físico y mental, se genera una protección especial.

\section{Artículo 13}

1. El niño tendrá derecho a la libertad de expresión; ese derecho incluirá la libertad de buscar, recibir y difundir informaciones e ideas de todo tipo, sin consideración de fronteras, ya sea oralmente, por escrito o impresas, en forma artística o por cualquier otro medio elegido por el niño.

2. El ejercicio de tal derecho podrá estar sujeto a ciertas restricciones, que serán únicamente las que la ley prevea y sean necesarias:

a) Para el respeto de los derechos o la reputación de los demás; o

b) Para la protección de la seguridad nacional o el orden público o para proteger la salud o la moral públicas. ${ }^{6}$

\section{Convención Internacional sobre la Eliminación de todas las Formas de Discriminación Racial}

La Convención Internacional sobre la Eliminación de todas las Formas de Discriminación Racial corresponde a un tratado internacional existente en materia de derechos humanos por la Organización de las Naciones Unidas y establece la restricción de todo tipo de discriminación racial inclusive en la utilización del derecho a la libertad de expresión.

\footnotetext{
${ }^{6}$ Organización de las Naciones Unidas ONU; Convención sobre los derechos del niño - Firmado en 1989
} 


\section{Artículo 4}

Los Estados partes condenan toda la propaganda y todas las organizaciones que se inspiren en ideas o teorías basadas en la superioridad de una raza o de un grupo de personas de un determinado color u origen étnico, o que pretendan justificar o promover el odio racial y la discriminación racial, cualquiera que sea su forma, y se comprometen a tomar medidas inmediatas y positivas destinadas a eliminar toda incitación a tal discriminación o actos de tal discriminación. ${ }^{7}$

\section{Convención Americana sobre Derechos Humanos}

La Convención Americana sobre Derechos Humanos denominada Pacto de San José de Costa Rica, establece la obligación a los estados miembros de proteger los derechos y libertades, adicionalmente crea dos organismos para su implementación y protección, la Comisión Interamericana de Derechos Humanos y la Corte Interamericana de Derechos Humanos.

\section{Artículo 13}

1. Toda persona tiene derecho a la libertad de pensamiento y de expresión. Este derecho comprende la libertad de buscar, recibir y difundir informaciones e ideas de toda índole, sin consideración de fronteras, ya sea oralmente, por escrito o en forma impresa o artística, o por cualquier otro procedimiento de su elección.

2. El ejercicio del derecho previsto en el inciso precedente no puede estar sujeto a previa censura sino a responsabilidades ulteriores, las que deben estar expresamente fijadas por la ley y ser necesarias para asegurar:

a. el respeto a los derechos o a la reputación de los demás, o

b. la protección de la seguridad nacional, el orden público o la salud o la moral públicas.

3. No se puede restringir el derecho de expresión por vías o medios indirectos, tales como el abuso de controles oficiales o particulares de papel para periódicos, de frecuencias

\footnotetext{
${ }^{7}$ Organización de las Naciones Unidas ONU; Convención Internacional sobre todas las formas de discriminación racial - Firmado en 1965 y entrado en vigor en 1969.
} 
radioeléctricas, o de enseres y aparatos usados en la difusión de información o por cualesquiera otros medios encaminados a impedir la comunicación y la circulación de ideas y opiniones.

4. Los espectáculos públicos pueden ser sometidos por la ley a censura previa con el exclusivo objeto de regular el acceso a ellos para la protección moral de la infancia y la adolescencia, sin perjuicio de lo establecido en el inciso 2.

5. Estará prohibida por la ley toda propaganda en favor de la guerra y toda apología del odio nacional, racial o religioso que constituyan incitaciones a la violencia o cualquier otra acción ilegal similar contra cualquier persona o grupo de personas, por ningún motivo, inclusive los de raza, color, religión, idioma u origen nacional. ${ }^{8}$

\section{Legislación nacional sobre libertad de expresión aplicable en el Ecuador Constitución de la República del Ecuador}

La constitución de la República del Ecuador del 2008 fue elaborada por la Asamblea Nacional Constituyente en el período 2007-2008, fue aprobada democráticamente mediante referéndum constitucional y publicado en el Registro Oficial como carta constitucional y máxima ley dentro del territorio ecuatoriano desde el 20 de octubre del 2008.

En esta norma constitucional define y proclama derechos, así como el cumplimiento de obligaciones y restricciones en:

\section{Sección tercera - Comunicación e Información}

Art. 16.-Todas las personas, en forma individual o colectiva, tienen derecho a:

Una comunicación libre, intercultural, Incluyente, diversa y participativa, en todos los ámbitos de la interacción social, por cualquier medio y forma, en su propia lengua y con sus propios símbolos (Nacional, Constitución de la República del Ecuador , 2008).

\footnotetext{
${ }^{8}$ Organización de Estados Americanos; Convención Americana sobre Derechos Humanos - Firmado en 1969 y entrada en vigencia en 1978
}

ISSN: 1390-9320, Edición Especial, diciembre 2019 
Art. 18.-Todas las personas, en forma individual o colectiva, tienen derecho a:

1. Buscar, recibir. Intercambiar, producir y difundir información veraz, verificada, oportuna, contextualizada, plural, sin censura previa acerca de los hechos, acontecimientos y procesos de interés general, y con responsabilidad ulterior.

2. Acceder libremente a la información generada en entidades públicas, o en las privadas que manejen fondos del Estado o realicen funciones públicas. No existirá reserva de información excepto en los casos expresamente establecidos en la ley. En caso de violación a los derechos humanos, ninguna entidad pública negará la información (Nacional, Constitución de la República del Ecuador , 2008).

Art. 19.- La ley regulará la prevalencia de contenidos con fines informativos, educativos y culturales en la programación de los medios de comunicación y fomentara la creación de espacios para la difusión de la producción nacional independiente (Nacional, Constitución de la República del Ecuador , 2008).

En el título 2 de los Derechos en su capítulo sexto los derechos de libertad proclamados en:

Art. 66. - Se reconoce y garantizara a las personas:

Numeral 6 - El derecho a opinar y expresar su pensamiento libremente y en todas sus formas y manifestaciones

Numeral 7 - El derecho de toda persona agraviada por informaciones sin pruebas o inexactas, emitidas por medios de comunicación social, a la correspondiente rectificación, replica o respuesta, en forma inmediata, obligatoria y gratuita, en el mismo espacio u horario.

Numeral 18 - El derecho al honor y al buen nombre. La ley protegerá la imagen y la voz de la persona.

Numeral 19 - El derecho a la protección de datos de carácter personal, que incluye el acceso y la decisión sobre información y datos de este carácter, así como su correspondiente protección. La recolección, archivo, procesamiento, distribución o difusión de estos datos o información requerirán la autorización del titular o el mandato de la ley.

Numeral 21 - El derecho a la inviolabilidad y al secreto de la correspondencia física y virtual; ésta no podrá ser retenida, abierta ni examinada, excepto en tos casos previstos en la ley, previa intervención judicial y con la obligación de guardará secreto de los asuntos ajenos al hecho que 
motive su examen. Este derecho protege cualquier otro tipo o forma de comunicación (Nacional, Constitución de la República del Ecuador , 2008).

\section{Código orgánico de la niñez y adolescencia}

\section{Art.59.- Derecho a la libertad de expresión.}

Los niños, niñas y adolescentes tienen derecho a expresarse libremente, a buscar, recibir y difundir informaciones e ideas de todo tipo, oralmente, por escrito o cualquier otro medio que elijan, con las únicas restricciones que impongan la ley, el orden público, la salud o la moral públicas para proteger la seguridad, derechos y libertades fundamentales de los demás. (Nacional, Código Orgánico de la niñez y adolescencia, 2010).

\section{Abusos a través de redes sociales basados en la libertad de expresión}

Con el ingreso del concepto de redes sociales utilizando tecnologías de información se presentan un compendio de actividades que en el Ecuador no se encuentran totalmente reguladas y cuyas normativas son incipientes, las TIC han generado actividades que bajo el escudo del derecho a la libertad de expresión amparados en tratados internacionales como en normativas nacionales en particular la Constitución de la República y la ley orgánica de comunicación vulneran derechos elementales.

\section{Acoso por Internet}

Cyberbulling - divulgación de información confidencial o falsa con el uso de medios de comunicación digitales (Communications, 2016).

Consiste en denigrar, amenazar e insultar a una persona de forma constante a través de mensajes en redes sociales, mensajes de email, de WhatsApp o aplicaciones semejantes. Esta conducta incluye el poner apodos, mandar fotos o vídeos humillantes o crear rumores sobre una persona, todo ello con la intención de que otras personas se sumen a la humillación pública que se está haciendo del afectado y difundan el contenido (Communications, 2016). 


\section{Delito contra el derecho al honor y buen nombre}

Artículo 182 COIP. - Calumnia. - La persona que, por cualquier medio, realice una falsa imputación de un delito en contra de otra, será sancionado con pena privativa de libertad de seis meses a dos años. No constituyen calumnia los pronunciamientos vertidos ante autoridades, jueces y tribunales, cuando las imputaciones se hubieren hecho en razón de la defensa de la causa. (Nacional, Código Orgánico Integral Penal, 2014).

\section{Acoso por Internet - Linchamiento mediático}

Linchamiento mediático - difusión de información que, producida de forma concertada y publicada reiterativamente con el propósito de desprestigiar a una persona natural o jurídica, o reducir su credibilidad pública. (Nacional, Ley Orgánica de Comunicación, 2015).

Art. 26.- Linchamiento mediático. - Queda prohibida la difusión de información que, de manera directa o a través de terceros, sea producida de forma concertada y publicada reiterativamente a través de uno o más medios de comunicación con el propósito de desprestigiar a una persona natural o jurídica o reducir su credibilidad pública. La Superintendencia de la Información y Comunicación podrá disponer, previa la calificación de la pertinencia del reclamo, las siguientes medidas administrativas:

\section{Ley orgánica de comunicación}

\section{Art. 26.- Linchamiento mediático. - Medidas}

1. La disculpa pública de la o las personas que produjeron y difundieron tal información.

2. Publicar la disculpa establecida en el numeral anterior en el medio o medios de comunicación, en días distintos, en el mismo espacio, programas, secciones, tantas veces como fue publicada la información lesiva al prestigio o la credibilidad de las personas afectadas (Nacional, Ley Orgánica de Comunicación, 2015). 
Estas medidas administrativas se aplicarán sin perjuicio de que los autores de la infracción respondan por la comisión de delitos y/o por los daños causados y por su reparación integral.

\section{Conductas delictivas reguladas y no reguladas en internet en el Ecuador}

Las conductas delictivas que se cometen con más frecuencia a través de Internet tienen que ver sobre todo con los siguientes aspectos:

- Menores.

- Amenazas, calumnias e injurias.

- Estafas a través del comercio electrónico.

- Vulneración de derechos de propiedad intelectual e industrial.

- Accesos a datos reservados de carácter personal.

- Acceso a secretos de empresa.

- Daños en sistemas informáticos.

- Venta de productos prohibidos a través de Internet.

- La apología del terrorismo y la xenofobia.

Conductas delictivas más comunes en relación al uso inadecuado de la libertad de expresión

- El ciudadano compartió su vida y su intimidad con alguien que en ese momento le hizo fotos íntimas. Ahora las ha publicado en Internet o se las envía a familiares o a cualquier persona con un ánimo claro de atentar contra su dignidad, menoscabando su fama o su imagen. Se tipificaría como delito de violación a la intimidad.

- Si se ha insultado a través de cualquier tipo de foros de debate o Chat, correo electrónico o en un Sitio Web, mediante expresiones que claramente lesionan la dignidad y estimación o menoscaba su fama. Se tipificaría como delito de injurias el cual no está tipificado en el COIP.

- Si por cualquier contenido que se ha difundido en Internet, a través de la publicación del mismo en una página Web, o su comunicación a través del correo electrónico, foros, Chat o 
cualquier otro medio, se acusa de haber cometido un delito que en realizad no ha cometido, Se tipificaría como delito de Calumnia del COIP

- Si se ha recibido a través de Internet, o se ha encontrado en un medio de Internet que se haya consultado, amenazas dirigidas a la persona, por las cuales se deduce un daño o perjuicio a su persona, y se le exige o no contraprestación de cualquier naturaleza. Se tipificaría como delito de intimidación.

- Si se tiene conocimiento de un sitio Web donde ofrecen o se comercializan imágenes de pornografía infantil, contenidos que incitan al terrorismo, a la violencia o al odio racial, conoce la dirección donde los contenidos se ofrecen. Se tipificaría como delito de pornografía infantil u otros.

- Si se ha conocido que un menor ha recibido un mensaje con contenidos pornográficos, puede tratarse de un delito de provocación sexual. Si se tiene conocimiento de que un menor ha recibido proposiciones de contactos sexuales a través de Internet o le han solicitado fotografías. Se tipificaría como delito de corrupción de menores.

\section{Actividades ilícitas tipificadas como delitos de redes sociales en el Código Orgánico Integral penal}

- Robo y/o suplantación de Identidad (212 COIP - No Delito Informático)

- Robots, Perfiles falsos

- Pornografía infantil (89 COIP No Delito Informático)

- Cyberbulling, Grooming, Sexting (No tipificados)

- Amenazas - revelación de secretos (179 y 180 No Delito Informático)

- Delitos cometidos contra la imagen (26 de la LOC No delito informático)

- Robo de Información - Phishing (190 tipificado en COIP - ambiguo) 
Tabla 1 - Actividades Tipificadas en el COIP

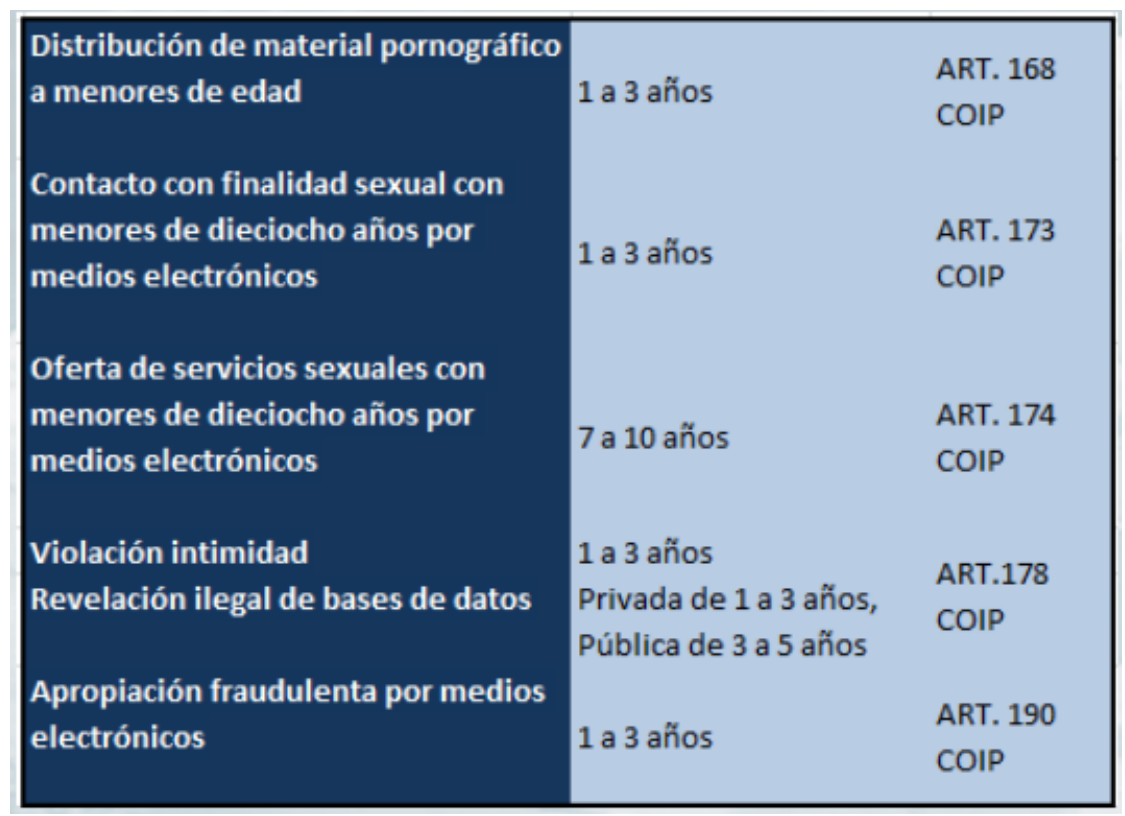

Fuente: Elaboración Propia

\section{Mitos de las redes sociales}

- Anonimato

- Registro IP - Operadores de Internet

- Registro en Redes sociales

- Libertad de expresión es absoluta en redes sociales (Tipificación de delitos)

- Las redes sociales son gratis (La información es utilizada para datos estadísticos y publicidad)

Existe el equivocado concepto del anonimato en las redes sociales y que por tanto existe la total libertad de expresión en las mismas; es importante señalar que aunque se haya institucionalizado y exista la percepción de que todo lo que existe o se realice en internet va de la mano con la libertad de expresión y por ende no tiene consecuencias legales o no se puede ubicar al generador de mensajes o publicaciones con la finalidad de desprestigiar, esto en la práctica no es cierto, todos los accesos que realizamos por Internet dentro del territorio ecuatoriano están 
codificados con un código único en la internet denominado IP pública y que hace las veces de cédula de identidad en la Web, es decir cualquier acceso, publicación, correo es gestionado a través de los proveedores de servicios de internet del país y por ende existe un historial de nuestros accesos en los mismos y que de la misma forma genera información para los diferentes sitios.

\section{Registro en las redes sociales}

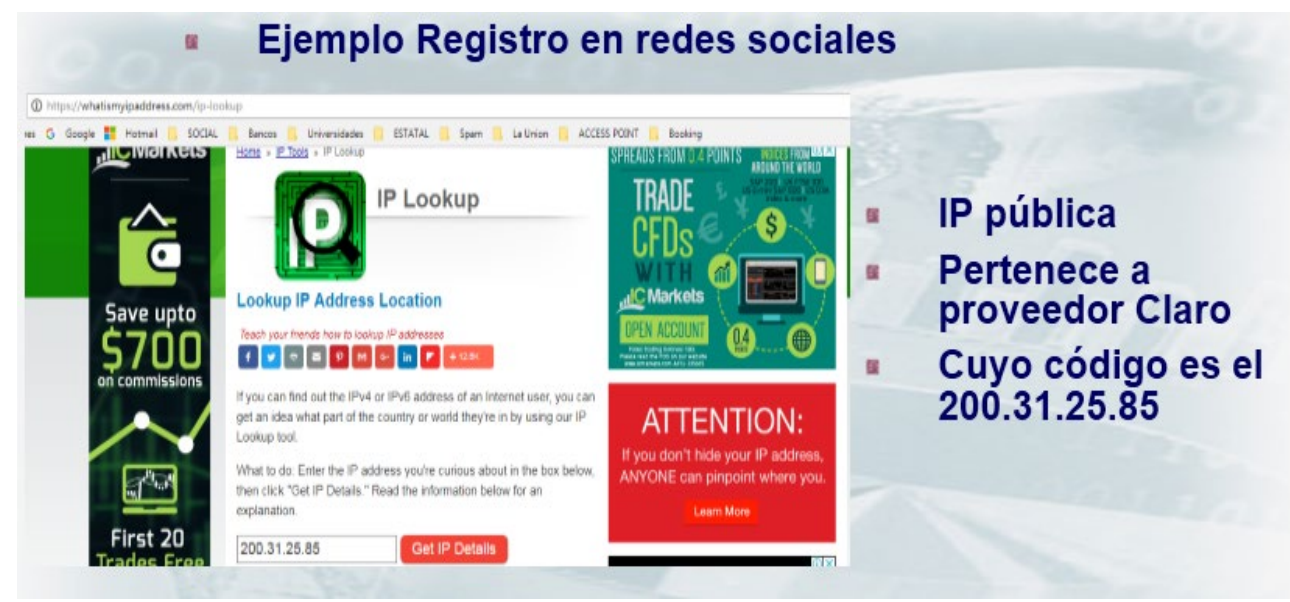

Figura 1. Registro en redes sociales

Fuente: Elaboración propia a partir del Sitio web reegister.com

- Guardan registro de tendencias y gustos en base a los me gusta.

- Te muestra con base en tus gustos productos o servicios.

- Guarda registro de tu IP pública de acceso amarrada a tus datos personales.

- Relaciona en base a las etiquetas

Todo acceso a internet se realiza por medio de un dispositivo electrónico el cual accede a la web por medio de un proveedor de internet que le asigna una dirección única IP la cual es rastreable y genera estadísticas para la red global. 


\section{Falencias en la normativa ecuatoriana en relación al uso de redes sociales La injuria y la calumnia como falencia en la normativa en el Ecuador}

Uno de los grandes inconvenientes en el Ecuador corresponde a la inexistencia del delito de injuria; actualmente la normativa penal solo incluye en el que corresponde a la sección de delitos contra el derecho al honor y buen nombre en sus artículos 182 y 368.

Artículo 182.- Calumnia. - La persona que, por cualquier medio, realice una falsa imputación de un delito en contra de otra, será sancionada con pena privativa de libertad de seis meses a dos años. No constituyen calumnia los pronunciamientos vertidos ante autoridades, jueces y tribunales, cuando las imputaciones se hubieren hecho en razón de la defensa de la causa. (Nacional, Código Orgánico Integral Penal, 2014).

Artículo 368.- Falsa incriminación. - La persona que realice acciones tendientes a incriminar falsamente a una o más personas en la comisión de los delitos de terrorismo y su financiación, será sancionada con la pena privativa de libertad de uno a tres años.

Se aplicará el máximo de la pena si los actos señalados en el inciso anterior son cometidos por una o un servidor público. (Nacional, Código Orgánico Integral Penal, 2014).

Lo que genera que si se arroga a una persona o institución actividades o situaciones que no estén tipificadas como delitos simplemente afectan al buen nombre, pero no tienen ningún efecto dado que no existe tipificación en la norma.

\section{Falta normativa en redes sociales en el Ecuador}

Las redes sociales tanto en el Ecuador como en el mundo hoy en día no son solamente espacios para relacionarse o comunicarse o relacionarse con otras personas; también es una poderosa herramienta para expresarse libremente. Pero al no existir una ley específica u orgánica que teorice las actividades ilícitas realizadas en este ámbito, así como la falta de tipificaciones y el no 
tener claro el procedimiento a realizar en este tipo de acciones generan que estas actividades no sean castigadas, dejando en estado de indefensión al ciudadano en estos casos.

\section{Falta preparación y herramientas en la administración de justicia}

La administración de justicia en el Ecuador para poder gestionar este tipo de actividades en redes sociales requiere de una formación exigente y detallada no solo en la materia en la que se requiere de su conocimiento sino también de procedimientos legales, legislación nacional e internacional, fundamentos de criminalística y psicología que le permitan un conocimiento más profundo de los casos analizados, ya que como profesional del derecho especialista es un garante de la verdad en un proceso.

Por lo expuesto, es clave que el administrador de justicia acredite experiencia, conocimientos teóricos y prácticos, habilidades en la aplicación de procedimientos y metodologías, y que sus informes sean metódicos y estructurales, entre otros.

El perfil del especialista en el ámbito de las actividades ilícitas en las redes sociales debe cumplir con algunas de las funciones que se destacan a continuación:

- Identificación y recolección de evidencias en medios magnéticos.

- Comprensión y práctica en procedimientos de revisión y análisis forenses.

- Comprensión de los aspectos legales y de privacidad asociados con la adquisición y revisión de medios magnéticos.

- Comprensión y práctica de mantenimiento de la cadena de custodia de la evidencia cuando se realiza una investigación informática.

- Comprensión de los diferentes sistemas de archivos asociados con sistemas operativos, acceso a archivos temporales, de cache, de correo electrónico, de Web, etc.

- Comprensión de aspectos de Internet.

- Comprensión de técnicas de rompimiento de contraseñas y claves de seguridad.

- Comprensión general de los temas relacionados con investigaciones forenses. 
Las investigaciones forenses aplicables a la informática, tecnología y Comunicaciones en el ámbito del derecho, requieren de profesionales con altos conocimientos en tecnologías de la información, que sean capaces de aplicar procedimientos científicamente probados válidos y reconocidos sobre las evidencias.

\section{MATERIALES Y MÉTODOS}

\section{Formulación}

¿Es suficiente la regulación existente en el ordenamiento jurídico ecuatoriano para el marco legal necesario para normar el ámbito de las redes sociales y que el derecho a la libertad de expresión no transgreda otros derechos?

\section{Sistematización}

1. ¿Qué es el derecho a la libertad de expresión?

2. ¿Es posible regular a las redes sociales?

3. ¿Cuáles son los beneficios de la regulación de las redes sociales?

4. ¿La regulación de las redes sociales vulnera el derecho a expresarse libremente?

5. ¿Por qué es importante la regulación de las redes sociales en el Ecuador?

\section{Desafíos ante la problemática}

En el ecuador debe realizarse un esfuerzo legislativo importante en materia del uso y gestión de las redes sociales por parte de la sociedad ecuatoriana; actualizando y generando nuevas normativas en materia del uso de las redes sociales, delimitando procesalmente las actividades ilícitas realizadas con las Tics, así como enmarcar el uso de la libertad de expresión ya sea de las personas naturales como las personas jurídicas siempre enmarcado en el cumplimiento de obligaciones internacionales en esta materia. 
Dentro de este análisis se espera obtener como propuestas:

\section{Propuesta de reforma al Código Orgánico de la niñez y adolescencia}

- Modificación de la jurisdicción y competencia

- Reforma incluyendo normativa delimitando la libertad de expresión en las redes sociales o plataformas virtuales

- Establecer concordancias con Ley Orgánica de delitos informáticos

\section{Propuesta de reforma a la ley Orgánica de Comunicación}

- Modificación de la jurisdicción y competencia

- Reforma incluyendo normativa delimitando el uso de las redes sociales o plataformas virtuales

- Establecer concordancias con Ley Orgánica de delitos informáticos

\section{Propuesta de reforma a la ley Orgánica de Telecomunicaciones}

- Modificación de la jurisdicción y competencia

- Reforma incluyendo el procedimiento administrativo para la recopilación de la prueba en los procesos de delitos tecnológicos.

- Generar obligatoriedad en las empresas portadoras y proveedores de Internet-ISP para la obligatoriedad y entrega de registros tecnológicos.

- Establecer concordancias con Ley Orgánica de delitos informáticos

\section{Propuesta de creación de organismo que genere estadística e información}

El Ecuador necesita la existencia de un organismo estatal que genere estadística y que constantemente procese información relevante sobre la libertad de expresión en el Ecuador con los siguientes lineamientos:

ISSN: 1390-9320, Edición Especial, diciembre 2019 
- Violaciones y ataques a la libertad de expresión

- Procesamiento de las Cifras de las agresiones a la libertad de expresión

- Tipo de agresiones contra la libertad de expresión y prensa en Ecuador

- Estadísticas de agresiones a la libertad de expresión actualizada y clasificada por tipos de agresión

- Los actores que más agresiones cometen contra la libertad de expresión en Ecuador

- Censura y autocensura en medios e internet en Ecuador

\section{Propuesta de una ley Orgánica de delitos informáticos}

El Ecuador necesita con urgencia ente una ley con carácter orgánico cuyo objeto sea la protección integral de los derechos de las instituciones públicas o privadas, así como del ciudadano en general de todas las actividades ilícitas que utilicen tecnologías de información y que vulneren los derechos amparados en la constitución, así como la prevención y sanción de los delitos cometidos mediante el uso de tecnologías de información, promoviendo la siguiente estructura.

- Definiciones

- Jurisdicción y competencia

- Ámbito de la Ley (Uso de las TICS y plataformas tecnológicas - redes sociales)

- Delitos contra la Propiedad

- Delitos contra la privacidad de las personas y de las comunicaciones (Relacionado al tema en cuestión)

- Delitos en contra de la protección del niño y adolescente

- Delitos contra el orden económico

- Establecer el procedimiento a realizar en estas actividades ilícitas.

\section{Propuesta de reforma al Código Orgánico Integral Penal - COIP}

Al realizar la propuesta de una ley de delitos informáticos, es imprescindible reformular algunas partes del COIP, promoviendo la inclusión y cambios de esta manera. 
- Modificación de la jurisdicción y competencia

- Reforma incluyendo normativa delimitando la libertad de expresión en las redes sociales o plataformas virtuales

- Inclusión y delimitación de la injuria dentro del cuerpo jurídico

- Establecer concordancias con Ley Orgánica de delitos informáticos

\section{CONCLUSIONES Y LIMITACIONES}

\section{Conclusiones}

a) Que la normativa del Ecuador en materia de redes sociales es incipiente y el tratamiento de ciertas actividades en estas plataformas no tiene una delimitación acorde; lo que produce que los administradores de justicia realicen su labor con las pocas herramientas que se tiene en el país, sin lograr resultados adecuados.

b) Que los niños, adolescentes y familias ecuatorianas están expuestos a diferentes actos realizados en estas plataformas virtuales debido a la falta de delimitación de las mismas.

c) Que al no existir normativa que regule la libertad de expresión en las redes sociales; ésta sirve de escudo para realizar acciones que atentan al derecho al honor y el buen nombre.

d) Que la función judicial en el Ecuador no tiene las herramientas jurídicas ni la capacitación en esta temática para un correcto desarrollo de la administración de justicia.

e) La falta de información histórica como estadística a nivel público y privado sobre las agresiones a la libertad de expresión.

\section{Limitaciones del estudio}

Este proceso de investigación se enfoca en la recopilación de información sobre el uso y abuso de la libertad de expresión en las plataformas virtuales denominadas redes sociales; para esto es necesario determinar las regulaciones existentes y las que se requieren ya sea a nivel de reformas legales o creación de nuevos cuerpos legales.

Como se ha establecido en este documento la regulación ecuatoriana en este ámbito es incipiente o ninguna; lo que genera que en el ordenamiento jurídico las sentencias con resultados 
acordes a la necesidad de la sociedad sean mínimos y por ende la jurisprudencia es casi inexistente.

Otra limitante es la falta de conocimiento legal-informático en los operadores de la función judicial y administración de justicia ecuatoriana en general; para poder solventar este inconveniente se revisará como fuente primaria los sucesos con mayor connotación a nivel periodístico en relación a los procesos que coartan la libertad de expresión en los medios; así como los sucesos que bajo el escudo de la libertad de expresión vulneran derechos amparados constitucionalmente y que no están siendo delimitados en el ordenamiento jurídico nacional; de la misma forma se revisaría en el ámbito internacional las mejores prácticas en legislaciones comparadas para poder aplicarlas al ámbito nacional.

\section{REFERENCIAS BIBLIOGRÁFICAS}

Communications, H. L. (2016). Marketing en redes sociales. Anaya Multimedia, 2017.

Estado, U. d. (2019). Informe de Evolución de Incidentes Tecnológicos (2019). Quito.

FBI. (2018). Manual Operativo FBI. Washington-USA.

Judicial, P. (2010). Ley Orgnánica del Poder Judicial. Quito.

López, D. (2018). Análisis Forense Digital. México: Ed.LIMUSA.

Nacional, A. (2008). Constitución de la República del Ecuador. Quito - Ecuador: CEP.

Nacional, A. (2010). Código Orgánico de la niñez y adolescencia.

Nacional, A. (2014). Código Orgánico Integral Penal. Quito-Ecuador: Registro Oficial. 
Nacional, A. (2015). Ley Orgánica de Comunicación. Quito: Registro Oficial.

Unidas, O. d. (2009). Tipificación de delitos informáticos. Informática Jurídica. 